\title{
Beberapa Faktor yang Berpengaruh terhadap Kejadian Diabetes Mellitus Tipe 2 pada Wanita Usia Subur (WUS) di RSUD Kota Madiun
}

\author{
Hanifah Ardiani", Suharyo Hadisaputro ${ }^{* *}$, Djoko Trihadi Lukmono ${ }^{* * *}$, Heri Nugroho ${ }^{* * *}$, Antono \\ Suryoputro ${ }^{* * * *}$ \\ "STIKES Bhakti Husada Mulia Madiun, ${ }^{* *}$ Politeknik Kesehatan Semarang, ${ }^{* * *}$ Fakultas Kedokteran \\ Undip, ${ }^{* * * *}$ Fakultas Kesehatan Masyarakat
}

\begin{abstract}
Background : Women of reproductive age with Diabetes Mellitus (DM) who were married having a risk complications of pregnancy, either on mother and her baby. Study on risk factors of $\mathrm{DM}$ in women of reproductive age was a rare, they have never done on women of reproductive age that married. The objective of this study was to prove some variables that influence to DM in women of reproductive age.

Method : An observasional analytic was conducted with case-control study design. Populations in this study were women of reproductive age 20-49 years that check blood sugar at Madiun Regional Hospital. The samples in this study were 54 cases and 54 controls by consecutive sampling. Data were analyzed by chi-square and logistic regression.
\end{abstract}

Results : Women of reproductive age with 2 and 3 quartile stress scores had risk 4,12 (95\% $\mathrm{CI}=1,42-11,92)$ and 5,64 $(95 \% \mathrm{CI}=1,19-16,55)$ greater for DM than the comparison group. Women of reproductive age with physical activity $<600$ MET had risk 4,33 times greater for DM than $\geq 600 \operatorname{MET}(95 \% \mathrm{CI}=1,71-10,96)$.

Conclusion :Variables levels of carbohydrate and fat consumption were not associated with DM. Physical activity and stress levels were evident influece DM occurence in women of reproductive age.

Keywords : Physical activity; stress; diabetes mellitus

*Penulis korespondensi : hanifah.ardiani@yahoo.com 


\section{Pendahuluan}

Diabetes mellitus (DM) merupakan salah satu penyakit metabolik yang ditandai dengan hiperglikemi akibat gangguan pada sekresi insulin, aktivitas insulin atau keduanya. ${ }^{1}$ DM pada Wanita Usia Subur (WUS) perlu diwaspadai karena WUS yang sudah menikah memiliki peluang untuk mengalami kehamilan. Wanita yang mengalami DM sebelum kehamilan lebih berisiko untuk melahirkan prematur, mengalami persalinan dengan induksi, melahirkan dengan operasi caesar, menderita hipertensi dan memerlukan rawat inap lebih lama di rumah sakit dibandingkan ibu hamil tanpa DM. ${ }^{2}$ DM sebelum kehamilan juga mempengaruhi kondisi bayi, yaitu bayi lebih berisiko untuk lahir mati, bayi lahir prematur, berat badan lahir tinggi, skor apgar rendah, resusitasi tingkat tinggi, dirawat di ruang perawatan intensif dan memerlukan rawat inap di rumah sakit lebih lama dibandingkan bayi yang lahir dari ibu tanpa DM. Selain itu, jika wanita dengan DM hamil, anak yang belum dilahirkannya juga memiliki risiko tinggi untuk mengalami DM pada saat dewasa. ${ }^{3}$

Tahun 2015 terdapat 199,5 juta wanita mengalami DM di dunia. Dua dari lima wanita dengan DM adalah WUS berdasarkan perhitungan lebih dari 60 juta wanita di dunia. ${ }^{4}$ Menurut data Riskesdas 2007, terdapat 3,6\% penderita DM pada perempuan usia reproduksi (15-49 tahun) di Indonesia pada tahun 2007. ${ }^{5}$ Menurut data Riskesdas 2007, Jawa Timur menempati posisi 9 DM pada WUS tidak hamil yaitu sebesar 5\%. ${ }^{6} \mathrm{DM}$ merupakan penyakit nomor satu pada instalasi rawat jalan Rumah Sakit Umum Daerah (RSUD) Kota Madiun (20132015), nomor satu pada instalasi rawat inap (2013) dan nomor dua pada instalasi rawat inap (2014-2015). Proporsi kasus baru DM pada WUS pada instalasi rawat jalan RSUD Kota Madiun yaitu sebesar 3,88\% pada tahun $2013,5,2 \%$ pada tahun 2014 dan $4,92 \%$ pada tahun 2015 . $^{7}$
Konsumsi karbohidrat sederhana seperti gula dapat meningkatkan kadar gula darah karena dapat dicerna dengan cepat. Konsumsi makanan yang menyebabkan peningkatan konsentrasi glukosa plasma postprandial dikaitkan dengan peningkatan konsentrasi asam lemak bebas dalam plasma. Asam lemak bebas dalam plasma juga berperan meningkatkan konsentrasi asetil KoA mitokondria yang menghambat piruvat dehidrogenase sehingga menurunkan oksidasi glukosa.

Data Riskesdas tahun 2007 menunjukkan bahwa sebanyak 16,7\% WUS dengan DM sering mengkonsumsi lemak.5 Lemak dalam makanan dapat meningkatkan konsentrasi glukosa dan kebutuhan insulin pada pasien DM tipe 1. ${ }^{9}$ Komposisi asam lemak dari makanan mempengaruhi komposisi fosfolipid jaringan, yang mungkin berhubungan dengan aktivitas insulin dengan mengubah fluiditas membran dan penanda insulin. $^{10}$

Aktivitas fisik menurun pada WUS, baik yang sedang hamil maupun yangtidak hamil. Penelitian di Polandia menunjukkan sebesar 23,08\% wanita berusia di atas 15 tahun dan $55,87 \%$ wanita yang sedang hamil memiliki aktivitas fisik yang rendah. ${ }^{11}$ Berdasarkan data Riskesdas 2007, sebesar $52,5 \%$ wanita yang mengalami DM juga memiliki aktivitas fisik yang kurang.5Aktivitas fisik yang cukup dapat membantu meningkatkan sensitivitas tubuh terhadap insulin dan menghindari kegemukan. ${ }^{12}$ Melalui olahraga dan aktivitas fisik, insulin akan bekerja lebih baik, sehingga glukosa dapat masuk ke dalam selsel otot untuk dibakar. ${ }^{13}$

WUS dapat mengalami stres terkait dengan pekerjaan, kehamilan, pernikahan dan ekonomi. Stres yang terjadi pada saat kehamilan dapat mencapai $34 \% .{ }^{14}$ Bahkan menurut penelitan di India, stres yang yang terjadi pada WUS dapat mencapai $69,5 \%{ }^{15}$ Stres dapat mengaktifkan glukokortikoid (seperti hormon kortisol) yang dapat meningkatkan output glukosa hati, menurunkan sekresi dan sensitivitas dari 
hormon insulin. Selain itu stres juga dapat meningkatkan akumulasi lemak tubuh, hipertensi dan dapat menyebabkan seseorang memiliki gaya hidup yang tidak sehat. ${ }^{16}$

DM pada WUS merupakan masalah yang penting karena proporsi kasus baru yang tinggi dan dampaknya juga berbahaya karena WUS yang sudah menikah memiliki peluang untuk hamil. Penelitian tentang faktor risiko kejadian DM pada WUS masih jarang dilakukan, bahkan belum pernah dilakukan pada WUS yang sudah menikah. Variabel gaya hidup termasuk tingkat aktivitas fisik, tingkat konsumsi karbohidrat, tingkat konsumsi lemak dan tingkat stres secara umum belum pernah diteliti pada WUS. Oleh karena itu, dilakukan penelitian tentang beberapa faktor yang berpengaruh terhadap DM pada WUS.

\section{Metode}

Penelitian ini merupakan penelitian obeservasional analitik dengan desain studi kasus kontrol. Lokasi penelitian di RSUD Kota Madiun pada bulan Mei-Juni 2017. Populasi penelitian adalah semua wanita usia subur (20-49 tahun) yang sudah menikah dan pernah periksa gula darah di RSUD Kota Madiun. Sampel kelompok kasus adalah wanita usia subur (20-49 tahun) sudah menikah yang baru didiagnosis DM berdasarkan pemeriksaan gula darah di RSUD Kota Madiun. Sampel kelompok kontrol yaitu wanita usia subur (20-49 tahun) sudah menikah yang pernah periksa di RSUD Kota Madiun dan tidak didiagnosis DM. Sampel dipilih dengan teknik consecutive sampling dengan jumlah sampel 54 kasus dan 54 kontrol berdasarkan rumus Lemeshow. Data primer diperoleh melalui wawancara dengan kuesioner. Data yang sudah dianalisis dengan chi-square dan regresi logistik disajikan dalam bentuk tabel dan narasi.
Diabetes mellitus untuk kelompok kasus didiagnosa berdasarkan kadar gula darah sewaktu plasma vena $>200 \mathrm{mg} / \mathrm{dL}$ disertai dengana gejala klasik (poliuria, polydipsia, polifagia dan penurunan berat badan tanpa penyebab pasti). Kelompok kontrol ditentukan berdasarkan hasil pemeriksaan gula darah sewaktu kapiler $<90$ $\mathrm{mg} / \mathrm{dl}$ serta tanpa keluhan klasik dengan alat Easy Touch GCU. Variabel tingkat stres diukur dengan menggunakan Perceived Stress Scale-14, tingkat aktivitas fisik dengan Global Physical Activity Questionnaire, tingkat konsumsi karbohidrat dan lemak diukur dengan Semiquantitative Food Frequency Questionnaire. Variabel tingkat stres, tingkat konsumsi karbohidrat dan tingkat konsumsi lemak dianalisis dengan mengkategorikan berdasarkan nilai kuartil. Variabel tingkat aktivitas fisik dibagi menjadi dua kategori, yaitu sesuai anjuran WHO ( $\geq 600$ MET) dan tidak sesuai anjuran WHO $(<600$ MET $)$.

\section{Hasil}

Karakteristik responden dalam penelitian ini yaitu sebagian besar kelompok kasus memiliki pendidikan tamat SMP (29,6\%), sedangkan kelompok kontrol sebagian besar memiliki tingkat pendidikan tamat perguruan tinggi $(37,0 \%)$. Jenis pekerjaan mayoritas responden yaitu ibu rumah tangga, baik pada kelompok kasus maupun kontrol. Rata-rata umur, skor konsumsi karbohidrat, skor konsumsi lemak, dan skor tingkat stres lebih tinggi pada kelompok kasus dibandingkan kelompok kontrol. Hasil secara lengkap disajikan pada Tabel 1. 
Tabel 1. Distribusi karakteristik subyek penelitian

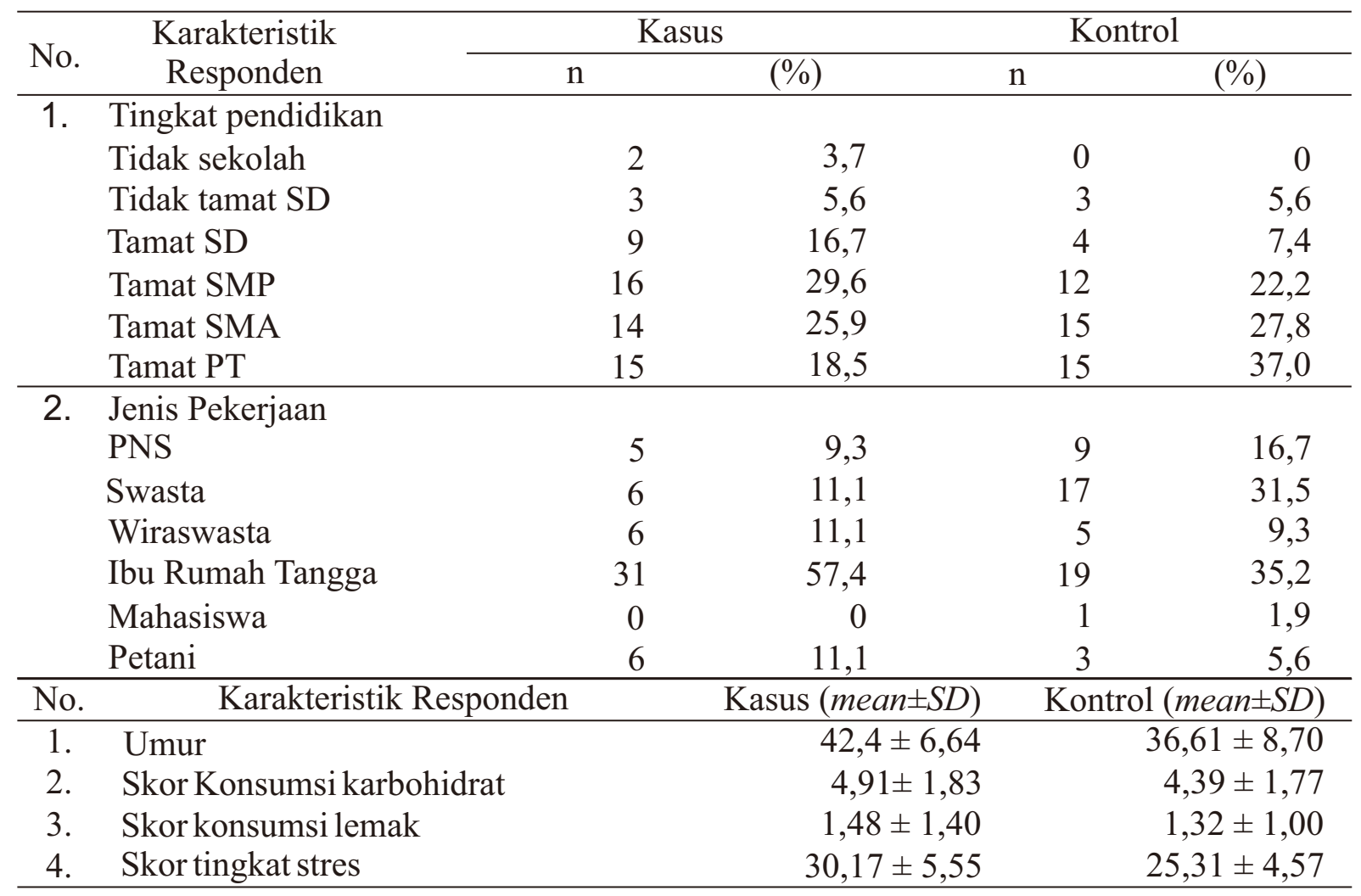

Tabel 2. Rangkuman hasil analisis bivariat

\begin{tabular}{clrrr}
\hline No. & \multicolumn{1}{c}{ Variabel } & OR & $95 \%$ CI & P \\
\hline 1. & Tingkat Konsumsi Karbohidrat & & & \\
& Q1 (Referensi) & 1,18 & $0,53-2,63$ & 0,683 \\
& Q2 & 1,39 & $0,63-3,12$ & 0,414 \\
& Q3 & & & \\
\hline 2. & Tingkat Konsumsi Lemak & & \\
& Q1 (Referensi) & & \\
& Q2 & & \\
& Q3 & 1,72 & $0,32-1,59$ & 0,414 \\
\hline 3. & Tingkat aktivitas fisik tidak sesuai & 3,50 & $1,52-8,06$ & $0,003^{* *}$ \\
& anjuran WHO (<600 MET) & & & \\
\hline 4. & Tingkat Stres & 5,79 & $2,22-15,08$ & $<0,001^{* *}$ \\
& Q1 (Referensi) & 2,89 & $1,32-6,31$ & $0,007^{* *}$ \\
& Q2 & & \\
& Q3 & & & \\
\hline
\end{tabular}

Sumber : Data Primer, 2017

Ket $:^{*}=$ Variabel yang menjadi kandidat dalam uji regresi logistic $(\mathrm{p}<0,25$

$* *=$ Variabel yang berhubungan dengan variabel dependen $(\mathrm{p}<0,05)$

sekaligus menjadi kandidat dalam uji regresi logistic 
Tabel 3. Hasil analisis multivariat

\begin{tabular}{clrlrl}
\hline No. & \multicolumn{1}{c}{ Variabel } & Nilai B & P & OR & 95\% CI \\
\hline 1. & Tingkat Stres Q3 & 1,729 & 0,002 & 5,64 & $1,92-16,55$ \\
2. & Tingkat Stres Q2 & 1,415 & 0,009 & 4,12 & $1,42-11,92$ \\
3. & Aktivitas fisik tidak sesuai anjuran & 1,466 & 0,002 & 4,33 & $1,71-10,96$ \\
& WHO $(<600$ MET) & $-1,519$ & & & \\
& Konstanta & & & \\
\hline
\end{tabular}

Sumber : Data Primer, 2017

Berdasarkan nilai $p$, tidak ada hubungan yang signifikan antara konsumsi karbohidrat kuartil 2 dan kuartil 3 dengan kejadian DM pada WUS. Tingkat konsumsi lemak baik pada kuartil 2 dan kuartil 3 juga tidak berhubungan dengan kejadian DM pada WUS. Analisis bivariat menunjukkan bahwa ada hubungan yang signifikan antara tingkat aktivitas fisik dengan kejadian DM pada WUS. WUS dengan tingkat aktivitas fisik tidak sesuai anjuran WHO (<600 MET) memiliki risiko 3,5 kali lebih besar $(95 \%$ $\mathrm{CI}=1,52-8,02)$ untuk menderita DM dibandingkan WUS yang memiliki aktivitas fisik sesuai anjuran WHO ( $\geq 600$ MET). Tingkat stres pada kuartil 3 berhubungan dengan kejadian DM pada WUS, tetapi tidak dengan tingkat stres kuartil 2. WUS dengan tingkat stres kuartil 3 memiliki risiko 3,52 kali lebih besar $(95 \% \mathrm{CI}=1,47-8,42)$ untuk menderita DM dibandingkan WUS yang memiliki tingkat stres di bawah kuartil 3.

Rangkuman hasil analisis bivariat dari berbagai variabel disajikan pada Tabel 2 .

Berdasarkan hasil analisis multivariat, variabel yang terbukti berpengaruh terhadap kejadian DM pada WUS yaitu tingkat stres dan aktivitas fisik. WUS yang memiliki skor stres pada kuartil 2 memiliki risiko 4,12 kali lebih besar $(95 \%$ $\mathrm{CI}=1,42-11,92)$ untuk mengalami DM. Tingkat stres pada kuartil 3 memiliki risiko 5,64 kali lebih besar (95\% CI=1,19-16,55) untuk mengalami DM dibandingkan kelompok pembanding. WUS yang memiliki aktivitas fisik tidak sesuai dengan anjuran WHO $(<600 \mathrm{MET})$ memiliki risiko 4,33 kali lebih besar (95\% CI=1,71-10,96) lebih besar untuk mengalami DM dibandingkan WUS dengan tingkat aktivitas fisik sesuai dengan anjuran WHO $(\geq 600$

MET).

\section{Pembahasan}

Hasil analisis multivariat menunjukkan bahwa tingkat stres terbukti sebagai faktor risiko kejadian DM pada WUS. WUS dengan tingkat stres pada kuartil 2 dan 3 masing-masing memiliki risiko 4,12 kali dan 5,64 kali lebih besar untuk mengalai DM dibanding kelompok pembanding. Hasil penelitian ini sesuai dengan penelitian kohort prospektif selama 12 tahun yang menunjukkan bahwa wanita dengan tingkat stres sedang dan tinggi memiliki risiko 2-3 kali lipat untuk menderita DM tiga tahun kemudian. ${ }^{17}$ Penelitian lain di Jepang juga menunjukkan bahwa wanita usia 40-69 tahun dengan tingkat stres tinggi berisiko 1,25 kali untuk menderita DM dibandingkan dengan wanita dengan tingkat stres rendah $(95 \%$ $\mathrm{CI}=1,01-1,56){ }^{18}$

Penelitian pada wanita yang berpartisipasi dalam Women's Health Study, tingkat stres kumulatif berhubungan positif dengan prevalensi DM. Analisis regresi logistik setelah mengontrol umur, ras, dan status sosial ekonomi menunjukkan peningkatan risiko DM pada kuartil tingkat stres. Kuartil 1 memiliki OR 1,26 (95\% CI=1,11-1,43), kuartil 2 memiliki OR 1,64 $(95 \%$ CI $=1,47-1,91)$ dan kuartil 3 memiliki $\mathrm{OR}=2,34 \quad(95 \% \mathrm{CI}=2,27-2,75) .{ }^{19}$ Sebuah penelitian pada wanita $>25$ tahun di Australia menunjukkan bahwa tingkat stres dapat memicu metabolisme abnormal pada glukosa pada wanita. ${ }^{20}$ 
Reaksi psikologis terhadap stres mengarah pada aktivasi hypothalamo-pituitaryadrenal (HPA) axis yang menyebabkan berbagai kelainan pada endokrin, seperti kortisol yang tinggi dan tingkat steroid seks rendah yang berlawanan dengan aktivitas insulin. Pada saat yang sama, terlihat peningkatan lemak visceral (ketebalan meningkat) yang memainkan peran penting dalam DM dengan berkontribusi dalam resistensi insulin. ${ }^{21}$ Stres menyebabkan produksi kortisol yang berlebih. Kortisol adalah suatu hormon yang kerjanya berlawanan dengan aktivitas insulin dan menyebabkan kadar gula darah tinggi. Jika seseorang mengalami stres berat, maka kortisol yang dihasilkan akan semakin banyak, hal ini akan mengurangi sensivitas tubuh terhadap insulin. ${ }^{22}$ Selain itu mood yang buruk juga berhubungan dengan pola makan dan penurunan aktivitas fisik. ${ }^{23}$

Hasil analisis multivariat menunjukkan bahwa WUS yang memiliki aktivitas fisik $<600$ MET per minggu memiliki risiko 4,17 kali untuk menderita DM dibanding WUS dengan aktivitas fisik $\geq$ 600 MET. Hasil penelitian ini sesuai dengan penelitian lain yang hasilnya menunjukkan bahwa wanita yang tidak melakukan latihan fisik memiliki risiko 1,74 kali untuk menderita DM dibandingkan yang melakukan latihan fisik $(95 \% \mathrm{CI}=1,72-$ 1,76). ${ }^{24}$ Penelitian kohort prospektif di Shanghai Cina selama 4,6 tahun menunjukkan bahwa wanita yang aktivitas fisiknya >1,99 MET-jam/hari/tahun memiliki risiko 0,65 kali untuk mengalami DM dibanding yang memiliki MET $<0,8$ $\mathrm{jam} / \mathrm{hari} / \mathrm{tahun}(95 \% \mathrm{CI}=0,45-0,95) .{ }^{25}$ Sebuah penelitian yang dilakukan di Norway juga menunjukkan hasil yang sejalan dengan penelitian ini. Wanita yang memiliki aktivitas fisik tinggi memiliki risiko $0,76 \mathrm{kali}$ untuk menderita DM dibandingkan yang tidak melakukan aktivitas fisik (95\% $\mathrm{CI}=0,61-0,95){ }^{26}$

Aktivitas fisik yang cukup dan latihan olah raga secara teratur dapat membantu meningkatkan sensitivitas tubuh terhadap insulin dan menghindari kegemukan. ${ }^{12}$ Pada waktu bergerak, otot-otot memakai lebih banyak glukosa sehingga kosentrasi glukosa darah akan turun. Melalui olahraga dan aktivitas fisik, insulin akan bekerja lebih baik, sehingga glukosa dapat masuk ke dalam sel-sel otot untuk dibakar. ${ }^{13}$ Sebuah studi eksperimental menghubungkan antara aktivitas fisik dan peningkatan sensitivitas insulin dan uptake glukosa. ${ }^{27}$

Hasil analisis bivariat menunjukkan bahwa tidak ada hubungan antara tingkat konsumsi karbohidrat baik pada kuartil 1, 2 dan 3. Tingkat konsumsi karbohidrat tidak dimasukkan dalam kandidat analisis multivariat karena memiliki nilai $\mathrm{p}>0,25$. Hasil penelitian berbeda dengan penelitian yang dilakukan di Jepang yang menunjukkan bahwa konsumsi karbohidrat berhubungan dengan peningkatan risiko diabetes pada responden yang memiliki indeks massa tubuh $\geq 25 \mathrm{~kg} / \mathrm{m}^{2} .28$

Studi potong lintang tentang konsumsi makanan melayu khas Jambi menunjukkan hasil yang berbeda. Penelitian tersebut menunjukkan bahwa ibu rumah tangga yang mengkonsumsi tinggi karbohidrat memiliki risiko 3,02 kali untuk menderita DM dibandingkan yang konsumsi karbohidratnya tidak tinggi (95\% $\mathrm{CI}=1,36-7,53) .{ }^{29}$ Penelitian lain di Cina juga menunjukkan bahwa wanita dengan konsumsi karbohidrat tinggi memiliki risiko 1,28 kali untuk menderita DM dibandingkan yang konsumsinya cukup (95\% CI=1,09$1,50) .{ }^{30}$ Hal ini juga tidak sejalan dengan penelitian lain yang menyatakan bahwa konsumsi tinggi karbohidrat memiliki risiko 1,26 kali lebih besar untuk menderita DM dibandingkan yang konsumsinya rendah $(95 \% \mathrm{CI}=1,07-1,49){ }^{31}$

Hasil penelitian ini berbeda dengan penelitian sebelumnya karena tingkat konsumsi karbohidrat antara kelompok kasus dengan kelompok kontrol setelah dikategorikan menjadi kuartil hampir sama antara kuartil 1, 2 dan 3. Jenis bahan pangan antara penelitian ini dengan penelitian lain juga berbeda. Selain itu, penelitian ini juga belum memperhatikan indeks glikemi dan muatan glikemi (glycemic load) sehingga penelitian yang akan datang diharapkan 
memperhitungkan indeks glikemi dan muatan glikemi agar hasilnya lebih spesifik.

Hasil analisis bivariat menunjukkan bahwa tidak ada hubungan antara tingkat konsumsi lemak baik pada kuartil 1, 2 dan 3 karena memiliki nilai $p>0,05$. Tingkat konsumsi lemak tidak dimasukkan dalam kandidat analisis multivariat karena memiliki nilai $\mathrm{p}>0,25$. Hasil penelitian ini sesuai dengan penelitian cross sectional yang menunjukkan bahwa konsumsi tinggi lemak tidak berhubungan terhadap kejadian DM pada ibu rumah tangga di Jambi $(p=0,945) .29$ Penelitian meta analisis juga menunjukkan hal yang sama, yaitu tidak ada pengaruh konsumsi tinggi lemak trans terhadap kejadian DM pada wanita. ${ }^{32}$

Namun hasil penelitian ini tidak sesuai dengan penelitian kohort prospektif selama 4,5 tahun menunjukkan responden yang mengkonsumsi lemak jenuh dan lemak hewan memiliki risiko 2 kali lebih besar untuk mengalami DM dibandingkan responden yang mengkonsumsi lemak jenuh dan lemak hewan dalam jumlah rendah. ${ }^{33}$ Hasil penelitian variabel tingkat konsumsi lemak pada studi berbeda dengan penelitian sebelumnya karena jenis bahan pangan lemak antara penelitian ini dengan penelitian lain juga berbeda. Penelitian ini juga belum membedakan konsumsi lemak berdasarkan jenisnya, sehingga jika penelitian selanjutnya membedakan konsumsi lemak berdasarkan jenis, hasilnya akan jauh lebih bermanfaat.

Penelitian ini memiliki keterbatasan, yaitu untuk menentukan kelompok kontrol menggunakan kadar gula darah sewaktu kapiler. Darah yang dianjurkan untuk digunakan mendiagnosis DM yaitu plasma darah dari vena dan dilakukan pemeriksaan tes toleransi glukosa oral (TTGO). Namun TTGO sangat sulit dilakukan, biaya mahal dan responden juga akan menolak untuk berpuasa dan kembali mengantri ke laboratorium rumah sakit keesokan harinya. Berdasarkan Perkeni tahun 2015, jika tidak memungkinkan dilakukan TTGO, maka screening dan diagnosis boleh berdasarkan darah kapiler sewaktu maupun puasa dengan nilai $<90 \mathrm{mg} / \mathrm{dl}$ untuk menentukan kelompok kontrol. Sehingga penelitian selanjutnya sebaiknya menggunakan darah plasma vena dan melakukan TTGO.

\section{Kesimpulan}

Aktivitas fisik dan tingkat stres terbukti berpengaruh terhadap DM pada WUS. Instansi kesehatan dapat meningkatkan promosi kesehatan tentang pencegahan DM pada WUS dengan berbagai media dan acara, misalnya membuat banner atau leaflet yang disediakan di fasilitas kesehatan untuk promosi upaya pencegahan DM dan bahayanya terhadap WUS.

\section{Ucapan Terimakasih}

Terimakasih kepada direktur RSUD Kota Madiun yang telah memberikan izin penelitian, perawat, dan staff di RSUD Kota Madiun serta enumerator yang membantu dalam pengambilan data.

\section{Datar Pustaka}

1. Ambady R, Chamukuttan Snahalatha AN. 2017. Classification and Diagnosis of Diabetes. In: Holt, Richard IG, Clive S. Cockram, Allan Flyvbjerg BJG, ed. Textbook of Diabetes 5th Edition. West Sussex UK: John Wiley \& Sons Ltd.pp. 23-28.

2. Australian Institute of Health and Welfare. 2010. Diabetes in Pregnancy : Its Impact on Australian Women and Their Babies. Canberra: Australian Institute of Health and Welfare.

3. Chivese T, Mahmoud W, Magodoro I, Kengne AP, Norris SA, Levitt NS. 2016. Prevalence of Type 2 Diabetes Mellitus in Women of Childbearing Age in Africa During 2000-2016: Protocol of a Systematic Review and Meta-Analysis. BMJ Open;6(12).pp.1-5

4. International Diabetes Federation. GDM Resources, Fact and Figures [Internet]. 2015 [cited 2017 Mar 8] 
Available from: http://www.idf.org/ wom en - and - diabetes/resource-centre.

5. Wahyuni S, Alkaff RN. 2013. Diabetes M ellitus pada Perempuan Usia Reproduksi di Indonesia Tahun 2007. Jurnal Kesehatan Reproduksi Litbangkes;3(1).pp.46-51.

6. Isnawati A, Raini M. 2012.Hipertensi dan Diabetes Mellitus pada Wanita Usia Subur (WUS) di Daerah Urban di Indonesia. Jurnal Biotek Medisiana Indonesia Litbangkes.pp.41-53.

7. Dinas Kesehatan Kota Madiun. 2016. SurveilansTerpadu RSUD Kota Madiun 2013-2015.

Marc A. Brown, Len H. Storlien, XuFeng Huang, Linda C. Tapsell, Paul L.

8. Else, Janine A. Higgins et al. 2010. Chapter 21: Dietary Fat and Carbohydrate Composition: Metabolic Disease: Carbohydrat and Lipid Balan ce. In: Fat Detection Taste, Texture, and Post Ingestive Effects. Boca Raton: CRC Press.pp.548-550.

9. Wolpert HA, Astrid AC, Stephanie AS, Garry MS. 2013.Dietary Fat Acu tely Increases Glucose Concentrations and Insulin Requirements in Patients With Type 1 Diabetes. Diabetes Care; 36(4).pp.810-816.

10. Steyn N, Mann J, Bennett P, Temple N, Zimmet P, Tuomilehto J, Lindstrom, J, et al. 2007. Diet, Nutrition and the Prevention of Type 2 Diabetes. Public $\mathrm{H}$ e a $1 \mathrm{t} \mathrm{h}$ Nutrition;7(1A).pp.47-165.

11. Wojtyla A, Kapka-Skrzypczak L, Bilinski P, Paprzycki P. 2011. Physical Activity among Women at Reproductive Age and During Pregnancy (Youth Behavioural Polish Survey YBPS and Pregnancy-related Assessment Monitoring Survay-PrAMS) Epidemiological Population Studies in Poland During the Period 20102011. Annals of Agricultural and Environmental Medic ine;18(2).pp. 365-374.

12. Tuomilehto J., Indstrom J., Eriksson J., Valle T. 2011. Prevention of Type 2 Diabetes Mellitus by Changes In Lifestyle Among Subjects With Im paired Glucose Tolerance. The New England Journal Medicine, Massachusetts Medical Society;344(18). pp.1343-1350.

13. Sugondo. 2008. Hidup Secara Mandiri dengan Diabetes Mellitus. Jakarta: Balai Penerbit FK UI.

14. Pantha S, Hayes B, Yadav BK, Sharma P, Shrestha A, Gartoulla P. 2014. Prevalence of Stress among Pregnant Women Attending Antenatal Care in a Tertiary Maternity Hospital in Kathmandu. Journal Women's Hea 1th Care;3(5).pp.1-6.

15. Parameaswari PJ, Ravanan R, Udayshankar PM, Kamini B. 2015. Stress among Women in Sub-Urban Area of South Chennai, India. Scholars Journal of Applied Medical Sciences (SJAMS), Scholars Academic and ScientificPublisher;3(1C).pp.217-220.

16. Heraclides A, Chandola T, Witte DR, Brunner EJ. 2009. Psychosocial Stress at Work Doubles the Risk of Type 2 Diabetes in Middle-Aged. Diabetes Care, American Diabetes Association; 32(12).pp.2230-2235.

17. Harris, Melissa, Alexis Hure, Christopher Oldmeadow, Judy Luu, Debora Loxton JA. 2017. Stress Increases The Risk of Type 2 Diabetes Onset in Women A 12-Year Longitudinal Study Using Causal Modelling. PLoS One;12(2).pp.1-13.

18. Kato M, Noda M, Inoue M, Kadowaki T. Psychological Factors, Coffee and Risk of Diabetes Mellitus among MiddleAged Japanese: a Population-Based Prospective Study in the JPHC Study Cohort. Endocrinology Journal, Japan;2009;56(3):459-68.

19. Butler, Jonathan Z, Alan Zaslavsky, David R Williams, Natalie Slopen, Aruna Pradhan, Julie Buring MAA. 2016. Abstract 18000 Cumulative Psychological Stress and Type II Diabetes Mellitus in Wom e n Circulation. Circulation, American Heart Association;134.pp.20.

20. Williams, Emily D. Dianna J. Magliano, Robyn J Tapp, Brian F. Oldenburg JES. 2013. Psychosocial Stress Predicts Abnormal Glucose Metabolism Diabe- 
tes, Obesity and Lifestyle (AusDiab) Study. Annals of Behavioral Medicine, Springer;46(1).pp.62-72.

21. Lloyd C, Smith J, Weinger K. 2005. Stress and Diabetes: A review of the links. Diabetes Spectrum;18(2).pp. 121-127.

22. Watkins PJ. 2005. ABC of diabetes 5th edition. Vol. 15: Ethnicity and Disease. London: BMJ Publishing Group.pp.19-25.

23. Hackworth N, Moore SM, Hardie EA, Critchley C, Buzwell S, Crafti N, et al. 2007. A risk Factor Profile for Pre-Diabetes: Biochemical, Behavioural, Psychosocial and Cultural Factors. Electronic Journal of Applied Psychology; 3(2).pp.14-26.

24. Ibe A, Smith TC. 2014. Diabetes in US Women on The Rise Independent of Increasing BMI and Other Risk Factors; a Trend Investigation of Serial Cross-sections. BMC Public Hea 1th, BioMed Central;14(1).pp.954.

25. Villegas R, Shu X, Li H, Yang G, Matthews CE, Leitzmann M. 2006. Physical Activity and The Incidence of Type 2 Diabetes in The Shanghai Women's Health Study. International Journal Epidemiology, International Epidemiology Association;35.pp.15531562.

26. Hjerkind KV, Stenehjem JS, Nilsen TIL. 2017. Adiposity, Physical Activity and Risk of Diabetes Mellitus : Prospective Data from The Population-based HUN Study, Norway. BMJ Open;7.pp.1-8.

27. Hawley JA, Lessard SJ. 2008. Exercise Training-Induced Improvements in Insulin Action. Acta $\mathrm{Ph}$ ysiology, Scandinavian Physiological Society;192(1).pp.127-135.

28. Sakurai, Masaru, Koshi N, Katsuyuki M, Toshinari T, Katsushi Yoshita, ShinYa N, et al,. 2016. Dietary Carbohydrate Intake, Presence of Obesity and The Incident Risk of Type 2 Diabetes in Japanese Men. Journal Diabetes Investigation; 7(3).pp.343-351.
29. Zulfah S. 2015. Konsumsi Makanan Khas Melayu Jambi sebagai Faktor Risiko Diabetes Mellitus Tipe 2 pada Ibu Rumah Tangga di Kelurahan Mudung Laut Kota Jambi. Semarang: Universitas Diponegoro.

30. Villegas R, Liu S, Gao Y, Yang G, Li H, Zheng W, et al. 2007. Prospective Stu dy of Dietary Carbohydrates, Glycemic Index, Glycemic Load, and Incidence of Type 2 Diabetes Mellitus in Middle-Aged Chinese Women. Arch Intern Med, American Medical Association;167(21).pp.2310-2316.

31. Halton, Thomas L, Liu Simin, Manso E, Hu Frank B. 2008. Low-Carbohydrate-Diet Score and Risk of Type 2 Diabetes in Women. American Journal Clinical Nutrition;87(2).pp.339-346.

32. Souza RJ De, Mente A, Maroleanu A, Cozma AI, Ha V, Kishibe T, et al. 2015. Intake of Saturated and Trans Unsatura ted Fatty Acids and Risk of all Cause Mortality, Cardiovascular Disease, and Type 2 Diabetes: Systematic Review and Meta-analysis of Observational Studies. The BMJ Open;351.pp. $1-16$.

33. Guasch-Ferre M, Becerra-Tomas N, Ruiz-Canela M, Corella D, Schroder H, Estruch R, et al,. 2017. Total and Subtypes of Dietary Fat Intake and Risk of Type 2 Diabetes Mellitus in The Prevencion con Dieta Mediterranea (PREDI- MED) Study. American Journal Clinical Nutrition;105(3). pp.723-35. 